\title{
ЦИТ: иа217-086
}

DOI: 10.21893/2415-7538.2017-06-1-086

УДК 004.4:629.4

\section{Сидорова Е.А., Железняк С.П., Подгорная С.О. ОРГАНИЗАЦИЯ ИНФОРМАЦИОННОГО ОБЕСПЕЧЕНИЯ СИСТЕМЫ АНАЛИЗА ЭНЕРГОПОТРЕБЛЕНИЯ НА ТЯГУ ПОЕЗДОВ}

Омский государственный университет путей сообщения, Россия, Омск, пр. Маркса 35, 644046

Sidorova E.A., Zheleznyak S.P., Podgornaya S.O. ORGANIZATION OF INFORMATION SUPPORT ANALYSIS SYSTEM OF ENERGY CONSUMPTION FOR TRACTION OF TRAINS

Omsk State Transport University, Russia, Omsk, prospect Marksa 35, 644046

Аннотащия. B статье рассмотрены особенности организачии информационного обеспечения системы, предназначенной для решения задач анализа потребления топливно-энергетических ресурсов на тягу поездов. Непременным условием для эффективного и качественного выполнения анализа расхода энергоресурсов является наличие достоверной и исчерпывающей информации по разным направлениям исследования. Правильно организованные u обработанные данные определяют точность и адекватность принятия управленческих решений для осуществления целенаправленного планирования энергосберегающей деятельности на различных уровнях организационной структуры ОАО «Российские железные дороги».

Ключевые слова: информачионное обеспечение, база данных, анализ, энергопотребление, тяга поездов.

Abstract. In the article the peculiarities of organization of information support system designed for solving problems of analysis of consumption of fuel and energy resources for train traction. A prerequisite for the effective and quality performance analysis of energy consumption is the availability of reliable and comprehensive information on different areas of research. Correctly organized and processed data to determine the accuracy and adequacy of management decision-making for the realization of targeted planning of energy saving activities at different levels of the organizational structure of JSC "Russian Railways".

Key words: information support, database, analysis, energy consumption, traction of trains.

\section{Вступление.}

Основная доля расхода топливно-энергетических ресурсов (ТЭР) на железнодорожном транспорте приходится на перевозочный процесс. В условиях рыночной экономики задача снижения удельного расхода ТЭР на единицу выполняемой работы приобретает первостепенное значение. Для достижения поставленной цели необходимо учитывать динамику изменения энергопотребления на тягу поездов и влияющих на него факторов. Решение этой задачи невозможно без эффективного функционирования системы управления энергозатратами, обеспечивающей непрерывный мониторинг 
расхода энергоресурсов для осуществления целенаправленного планирования энергосберегающей деятельности [1]. При этом значительная роль отводится объективному и научно обоснованному анализу условий и результатов выполнения перевозочного процесса на различных уровнях организационной структуры ОАО «РЖД».

\section{Основной текст.}

Целью анализа расхода ТЭР на тягу поездов является определение изменения фактических показателей энергопотребления относительно плановых заданий, норм и результатов прошлого периода, выявление причин расхождения полученных значений и разработка мероприятий по эффективному использованию ТЭР. Непременным условием для качественного выполнения анализа является своевременное предоставление необходимой, достоверной и достаточной информации. От точности получаемых в процессе анализа результатов зависит правильность и адекватность принятия управленческих решений [2]. Применение информационных технологий позволяет повысить эффективность аналитической работы и создать рационально организованное информационное обеспечение, определяющее порядок поступления исходной информации, принципы ее организации и формы представления результатов.

Основу информационного обеспечения системы анализа энергозатрат на тягу поездов составляет база данных (БД), структура которой определяется составом и характеристиками учитываемых показателей, особенностями выполнения их обработки и информационных взаимосвязей.

Источником информации для выполнения анализа расхода ТЭР являются данные статистической отчетности об основных показателях эксплуатационной работы и энергопотреблении, сбор и обработка которых осуществляются на каждом уровне организационной структуры ОАО «РЖД» (эксплуатационное локомотивное депо, железная дорога, сеть железных дорог). Для обеспечения дальнейшего эффективного анализа исходные показатели разделяются по видам тяги, видам движения, типам и сериям тягового подвижного состава (ТПС), направлениям перевозок в границах участков работы локомотивных бригад.

Специфика анализа энергозатрат на тягу поездов определяется большим количеством и разнообразием влияющих эксплуатационных факторов, к которым относятся:

- показатели использования локомотива - средняя масса поезда и средняя техническая скорость в грузовом, пассажирском, пригородном и хозяйственном видах движения; средняя нагрузка на ось грузового вагона в грузовом и хозяйственном видах движения; коэффициент участковой скорости и доля порожнего пробега вагонов в грузовом движении;

- объемы перевозочной работы по видам движения;

- объемы перевозочной работы по направлениям в грузовом, пассажирском и пригородном видах движения;

- структура эксплуатируемого парка локомотивов;

- время простоя локомотивов в ожидании работы, количество задержек у 
запрещающего сигнала светофоров, количество неграфиковых остановок, количество случаев проследования мест с ограничением скорости;

- время нагона опоздания поездов в пассажирском и пригородном видах движения;

- объем энергии рекуперации;

- температура атмосферного воздуха и т. д.

Каждый из перечисленных показателей оказывает различное влияние на расход ТЭР и должен быть учтен при выполнении анализа энергозатрат.

Результативность выполнения статистического анализа зависит не только от характера используемой информации, но и от оптимальной организации информационных потоков при работе с базой данных. Накопленный опыт исследований авторов статьи в данной области позволил установить, что для реализации поставленных задач все рассматриваемые показатели необходимо систематизировать в БД по следующим группам, сформированным по принципу соответствия данных единой структуре, семантическому содержанию и информационной направленности:

- параметры настройки системы;

- нормативно-справочная информация;

- таблицы исходных данных;

- вспомогательные таблицы, включающие вычисляемые показатели, отсутствующие в исходных таблицах, но необходимые для выполнения оперативного анализа энергозатрат;

- служебные таблицы, обеспечивающие поддержку сервисных режимов системы.

Отличительной особенностью накопления данных в БД является существенно различающийся объем хранимой информации, степень детализации которой определяется уровнем управления энергопотреблением и спецификой выполняемой работы. Различная форма представления однотипных данных в разных источниках существующей системы оперативной и статистической отчетности ОАО «РЖД» усложняет процесс их интеграции в БД. Обоснованность принятия управленческих решений в значительной степени зависит от качества, полноты и эффективной систематизации представляемой информации. Например, на вышестоящих уровнях достаточно хранить только агрегированные показатели, а на линейном уровне потребность в подробной детализации данных по отдельным категориям обусловлена необходимостью оперативного управления энергопотреблением.

Указанные особенности выполнения анализа на разных организационных уровнях представляют определенную сложность по обеспечению рациональной структуры и эффективного функционирования единой БД. С целью обеспечения проведения оперативного анализа по отдельным направлениям исследования, получения общих или детализированных данных на различных уровнях управления целесообразно исходные данные представлять в БД не одной таблицей, а использовать структурированные табличные формы, содержащие сгруппированные данные по признакам их взаимосвязей и информационной потребности управления энергопотреблением (рис. 1). 


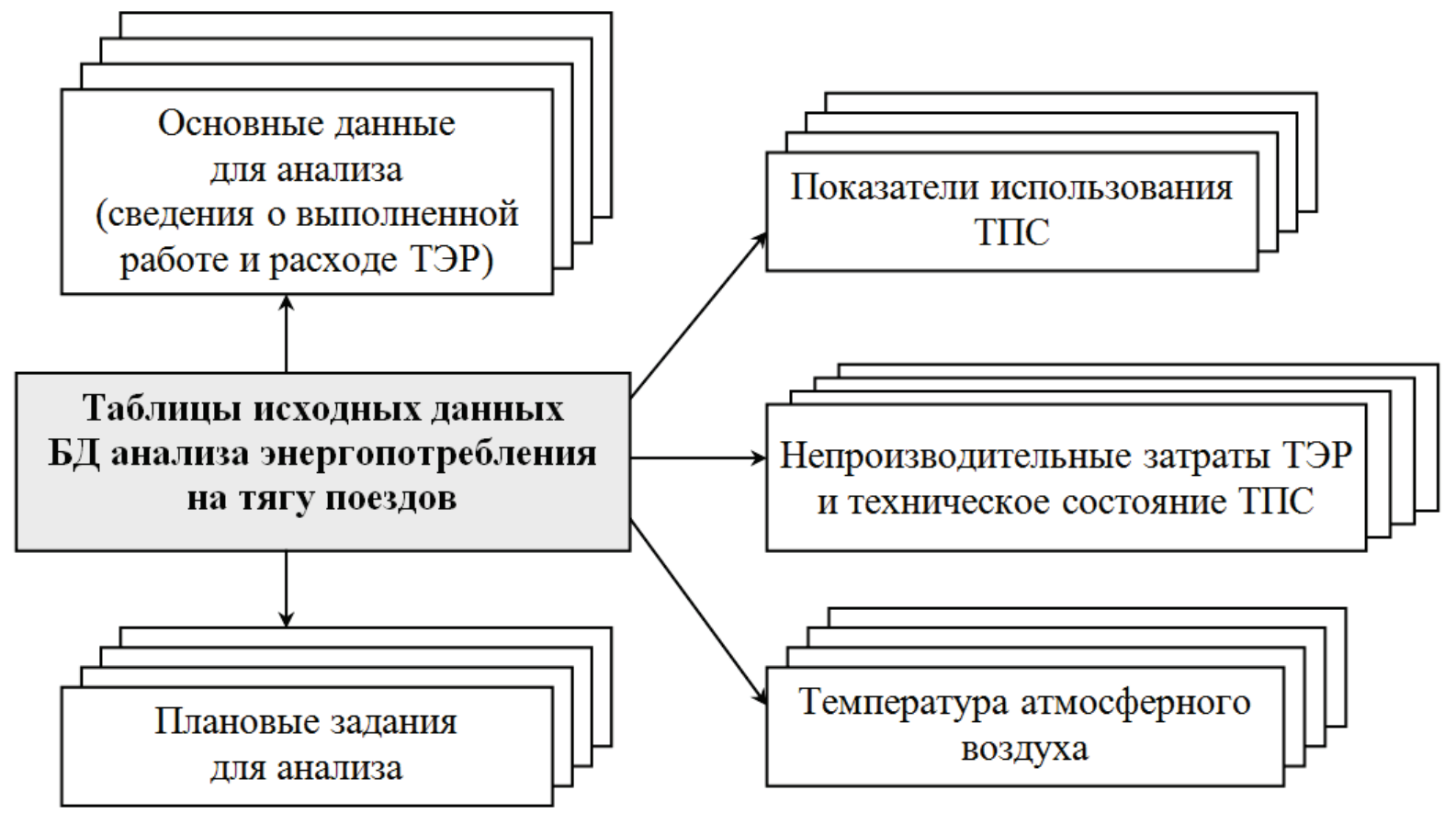

\section{Рис. 1. Состав таблиц исходных данных системы анализа энергопотребления на тягу поездов}

Для реализации унифицированной структуры БД, позволяющей применять ее на любом уровне иерархии структурного подразделения, необходимо предусмотреть наличие специальных инструментов, позволяющих сформировать требуемые отчеты в точном соответствии с информационными потребностями пользователя любого уровня, но при этом сократить количество запрашиваемых параметров.

Исходные данные статистической отчетности содержат значения эксплуатационных показателей, необходимые для анализа и прогнозирования расхода ТЭР. Кроме того, в структуру БД должны быть включены показатели, имеющие сложный алгоритм расчета и значения которых требуется хранить накопительным итогом за разные периоды. Помимо исходных данных в таблицах БД требуется дополнительно отображать расчетные показатели (например, удельный расход энергии), позволяющие оперативно выявить тенденции изменения энергопотребления.

Учет влияния каждого эксплуатационного фактора на изменение расхода ТЭР оценивается с помощью специальных коэффициентов влияния [3], которые определяются для каждого типа ТПС и анализируемого календарного периода по довольно сложным алгоритмам. Для выполнения многовариантных расчетов с одними и теми же коэффициентами необходимо обеспечить хранение в БД последних рассчитанных коэффициентов, а также предусмотреть возможность работы с коэффициентами влияния, заданными вышестоящим подразделением или определенными по различным методикам.

Важной составляющей информационного обеспечения системы анализа энергопотребления является нормативно-справочная информация (НСИ), предназначенная для пояснения и расшифровки данных, исключения 
неоднозначности при выполнении расчетов и формировании отчетов [4]. В зависимости от направления использования, хронологии и способа заполнения справочники систематизируются по следующим категориям: виды движения, направления перевозочной работы, типы и серии ТПС, нормы удельного расхода ТЭР и др. Грамотно организованная НСИ обеспечивает системность данных, согласованность и консолидацию показателей. Характерной особенностью анализа энергопотребления на различных иерархических уровнях является необходимость значительной детализации информации по выделенным категориям исследования и обобщения показателей по малодеятельным направлениям работы. Нерациональное определение таких категорий приводит к многократному росту объема отчетов, делает работу с ними крайне неэффективной, а также приводит к резкому увеличению времени вычислений. Для решения этой задачи необходимо предусмотреть в НСИ специальные поля и признаки, характеризующие значимость категорий анализа.

Существенную роль в организации информационного обеспечения системы анализа энергозатрат играет наличие эргономичного интерфейса, реализующего интерактивный режим работы пользователя с БД. Использование унифицированного набора диалоговых окон и гибкой системы навигации даст возможность пользователю максимально удобно выполнять стандартные операции поиска, сортировки, выборки информации в разных режимах, производить первичный анализ данных, что в конечном итоге определяет степень юзабельности работы с БД и способствует повышению эффективности выполнения анализа энергозатрат.

Таким образом, информационное обеспечение системы анализа энергопотребления на тягу поездов следует рассматривать как совокупность модулей, реализующих следующие режимы:

- ввод и обработку исходной информации, формирование и накопление на ее основе локальной БД;

- эффективную работу с данными БД;

- ведение нормативно-справочной информации;

- получение выходных аналитических таблиц оценки влияния эксплуатационных факторов на расход ТЭР;

- сервисные возможности по архивации, поиску, сохранению, восстановлению информации и обработке ошибочных ситуаций и др.

\section{Заключение.}

Рассмотренные принципы организации информационного обеспечения системы анализа энегозатрат на тягу поездов обеспечивают проведение качественного и эффективного анализа расхода ТЭР на любом уровне организационной структуры ОАО «РЖД» и реализованы в БД автоматизированной информационной системы анализа и прогнозирования расхода ТЭР на тягу поездов [5].

Литература:

1. Белов А.А., Федоров М.О. Роль информационного обеспечения в 
системе энергосбережения предприятия. Вестник ИГЭУ. 2005. Вып. 4. С. 24-30.

2. Лялькова Е.Е. Информационные источники управленческого анализа // Управление экономическими системами: электронный научный журнал. 2016. № 8. URL: http://www.uecs.ru/ekonomicheskiy-analiz/item/4050-2016-08-11-06-4339.

3. Сидорова Е.А., Подгорная С.О. Влияние показателей использования локомотивов на расход энергоресурсов в грузовом движении // Транспорт Урала. 2016. № 1(48). С. 41-45.

4. Сидорова Е.А., Железняк С.П. Организация нормативно-справочной информации в системе анализа энергозатрат на тягу поездов // Математическое моделирование и расчет узлов и устройств объектов железнодорожного транспорта: Межвузовский тематический сборник научных трудов. Омск. Омский государственный университет путей сообщения. 2012. С. 46-50.

5. Сидорова Е.А., Подгорная С.О., Железняк С.П. Структура базы данных системы анализа энергозатрат на тягу поездов // Новая наука: от идеи к результату: Международное научное периодическое издание по итогам Международной научно-практической конференции (29 июня 2016 г., г. Сургут) / в 2 ч. Ч.2. Стерлитамак: АМИ. 2016. С. 161-165.

Статья отправлена: 09.06.2017 г.

( С Сидорова Е.А., Железняк С.П., Подгорная С.О.

\section{ЦИТ: иа217-094}

DOI: 10.21893/2415-7538.2017-06-1-094

УДК 004.023

АВТОМАТИЗАЦІЯ РОБОТИ ПРОГРАМ РОЗРАХУНКІВ

Національний технічний університет Украйни „Київський політехнічний інститут імені Ігоря Сікорського”,

Киї, пр. Перемоги 37, 03056

Bondarenko $\mathbf{O}$.

AUTOMATION OF THE CALCULATION PROGRAMS

National Technical University of Ukraine "Igor Sikorsky Kyiv Polytechnic Institute", Kyiv, ave. Pobedy, 37, 03056

Аннотащия. В роботі наведено результати аналізу формування діаграми спрямованості фазованої антенної решітки. Діаграма спрямованості $\epsilon$ електронно-керована в азимутальній площині, змінюючи положення привідних елементів $i$ за рахунок динамічного додавання $i$ видалення відбивачів $i$ напрямлячів. Дизайн антени складається з 17 елементів, що складаються $з$ ведених елементів та рефлектору: 16 елементів були поміщені по колу $і$ ще один елемент є ииліндричним екраном поміщеним всередині кола. Моделювання проводилося иляхом зміни кількості активних елементів в масиві. Для кожного моделювання були один, три або п'ять активних елементів, які забезпечували напрямок променю в потрібному напрямку.

Ключові слова: антенна решітка, діаграма спрямованості, керування 